\title{
Continuous dynamic recrystallization (CDRX) model for aluminum alloys
}

\author{
Giovanni Maizza ${ }^{1, *}$ (D), Renato Pero $^{2}$ (D), Maria Richetta ${ }^{2}$ (D), and Roberto Montanari ${ }^{2}$ (D) \\ ${ }^{1}$ Department of Applied Science and Technology, Politecnico di Torino, Turin, Italy \\ ${ }^{2}$ Department of Industrial Engineering, University of Rome "Tor Vergata", Rome, Italy
}

Received: 1 July 2017

Accepted: 21 November 2017

Published online:

27 November 2017

(C) Springer Science+Business Media, LLC, part of Springer Nature 2017

\begin{abstract}
The control of a microstructure, during and after hot forming, is crucial to tailor optimum mechanical properties for specific applications. Recrystallization is a key process which may contribute to a great extent to microstructure development. Dynamic recrystallization is becoming an attracting research area to investigate novel hot forming routes in order to maximize the performance of aluminum products while shortening the time required for manufacturing. A continuous dynamic recrystallization (CDRX) mathematical model was developed by GourdetMontheillet (GM) to predict the inherent phenomena of an AA1200 alloy. In the present work, the original GM model has been extended and applied to study CDRX in a 5052 aluminum alloy. The proposed model embodies a solid solution and second phase strengthening, through newly estimated kinetic factors and a kinetic constant, respectively, to discern the CDRX behavior of 5052 aluminum alloy compared to AA1200. The latter kinetic constant relies on the KocksMecking-Estrin (KME) theory. The input law of the fraction of high angle boundaries $\left(f_{\mathrm{HAB}}\right)$, as a function of strain $(\varepsilon)$ (but independent of temperature and strain rate), is defined as the best fitting function of the experimental data. The results are presented in terms of stress-strain curves, dislocation density, and (sub) grain size, as these are important design parameters from an industrial and engineering viewpoint. The model has been validated successfully, from both a qualitative and quantitative point of view, against various literature data sources and tests (e.g., hot compression, hot plane strain compression, and equal channel angular pressing) pertaining to the 5052 alloy and other similar Al-Mg alloys.
\end{abstract}

\section{Introduction}

Scientific and industrial interest in the use of aluminum alloy sheets for the automotive, aircraft, and machinery fields is expanding considerably. The control of a microstructure, during and after hot forming, is crucial to obtain the optimum mechanical properties in relation to the final applications. Their optimization can reduce costs and production times. Computational models can help speed up the setting

Address correspondence to E-mail: maizza@polito.it 
up of the process in order to tailor the alloy composition, properties, and microstructure on the basis of the final applications.

The hot rolling of aluminum alloys has been studied both experimentally and theoretically [1-3]. Static and dynamic recrystallization processes are the basic mechanisms that are used to control a microstructure. In a discontinuous static recrystallization (DSRX) process [4], when a strain-hardened metal is heated above the recrystallization temperature, new grains may nucleate and then grow. In hot rolling, DSRX takes place both during annealing and immediately after hot plastic deformation, e.g., during the inter-pass time $[1,5]$.

Dynamic recrystallization can be classified as discontinuous (DDRX), continuous (CDRX), or geometric (GDRX) dynamic recrystallization $[4,6]$. DDRX is characterized by two steps: nucleation and growth. It does not usually occur in high stacking fault metals, like aluminum alloys, owing to their high tendency to recover. Nevertheless, DDRX has been observed in ultra-high purity aluminum [7, 8]. Constituent particles of a sufficiently large size can stimulate nucleation and can also promote DDRX [9]. In CDRX, new recrystallized grains form as a result of a progressive increase in the misorientation angle of subgrains with low-angle boundaries [4, 10]. GDRX was first introduced by McQueen [11] as the phenomenon that characterizes the formation of subgrains when the original grain boundaries progressively become serrated.

De Pari and Misiolek [12] showed that the main dynamic recrystallization phenomenon that occurs over the surface during the hot rolling of AA6061 is CDRX. GDRX may also occur, but it requires higher strains before remarkable effects become visible.

Despite the considerable amount of research conducted on CDRX in aluminum alloys at a high temperature, only a few modeling works have been proposed [13-16].

The early CDRX models applied to hot deformation [13] invoked grain boundary sliding and crystallite switching as the main mechanisms. Such mechanisms can only be considered well-founded in superplastic deformation conditions; therefore, it has not been possible to achieve quantitative agreements through experiments [17].

A new approach to the modeling of CDRX was introduced by Gourdet [14]. Initially, the model was applied to AA1199, AA1200, and AA5052 while relying on numerous assumptions, which made the early model hard to apply to real alloys. Later, Gourdet and Montheillet (GM) [15] developed a more reliable CDRX model, which is characterized by: (a) simplicity, (b) a small number of physical parameters, (c) the accounted deformation mechanisms in hot compression, described in the model, are realistic of such industrial processes as hot rolling. The model was able to describe the plastic behavior of AA1200 during a hot compression test (HCT) in terms of stress-strain curves, evolution of the subgrain size, dislocation density, low angle boundary (LAB) distribution and fraction of LABs, and high angle boundaries (HABs). They assumed that hot plastic deformation is the result of two contributions: strain hardening and dynamic recovery on the one hand, and grain boundary migration on the other. Dynamic recrystallization effects were evaluated in terms of increases in the misorientation angle of LABs and grain refinement. The grain refinement and the related stress-strain curves they predicted were in qualitative agreement with the results of previous experiments conducted over a wide range of temperatures and strain rates.

Subsequently, the GM theory was applied, using FEM simulations, to the study of changes in the grain structure over the surface of 6061 aluminum alloy during hot rolling and hot torsion [12].

Le and Kochmann [16] applied the thermodynamic theory [18] as an alternative to study CDRX during quasi-static plastic deformation, induced by hot equal channel angular pressing (ECAP), for the case of a "generic aluminum" alloy. The main internal variables considered in the so-called LK model were dislocation density and grain size. The fraction of the plastic work stored in the microstructure of the material was related to the internal variables and temperature. The outcomes of the LK model were in qualitative agreement with those of the ECAP experiments, in terms of average grain size and dislocation density. However, the strain rate dependence was neglected, due to the assumption of a quasi-static processing condition.

In summary, the LK model worked fine for a "generic aluminum" under very large hot strain processes, such as ECAP, whereas the GM model was applied to AA1200 under the typical strain rate of industrial processes, although it was not experimentally validated. 
The primary aims of this paper have been to extend the original CDRX model [15], from AA1200 to wrought aluminum alloys of industrial relevance (e.g., AA5052), during hot working conditions with low-to-moderate strain rates, and to obtain its qualitative and quantitative experimental validation against literature data. As online hot rolling data are rare, the experimental validation has involved simulated hot rolling data collected from laboratory devices (e.g., Gleeble and the like), essentially under plane strain hot compression, uniaxial hot compression, and equal channel angular hot pressing conditions. This approach will represent a first step toward the construction of a suitable CDRX model that can be used to control the microstructure and properties of wrought aluminum alloys in actual industrial hot rolling processes. As the predicted fraction of HABs $\left(f_{\mathrm{HAB}}\right)$ has been found to not be so realistic [19], the proposed extended GM model will attempt to overcome such limitations.

\section{Original (background)}

The GM model has three types of main variables [15]: internal, physical, and independent. The average subgrain size $(D)$, dislocation density $\left(\rho_{i}\right)$, misorientation angle $(\theta)$, and $\mathrm{LAB}$ distribution $(\varphi(\theta, \varepsilon))$ are internal variables. The temperature $(T)$ and strain rate $(\dot{\varepsilon})$ are physical variables. The time $(t)$, which is given by the ratio of the strain $(\varepsilon)$ to the strain rate, is the independent variable.

During hot deformation, dislocation density increases due to the operation of dislocation sources that leads to strain hardening [4] and decreases due to annihilation as a result of dynamic recovery:

$\frac{\mathrm{d} \rho_{i}(\varepsilon)}{\mathrm{d} \varepsilon}=h(\dot{\varepsilon}, T)-r(\dot{\varepsilon}, T) \rho_{i}(\varepsilon)$,

where $h$ and $r$ are the strain hardening and recovery parameters, respectively.

As the absorption of lattice dislocation may also be due to the migration of grain boundaries [14], Eq. (1) must include an additional term:

$$
\begin{aligned}
\frac{\mathrm{d} \rho_{i}(\varepsilon)}{\mathrm{d} \varepsilon}= & h(\dot{\varepsilon}, T)-r(\dot{\varepsilon}, T) \rho_{i}(\varepsilon) \\
& -\frac{\rho_{i}(\varepsilon) f_{\mathrm{HAB}}(\varepsilon) v_{\mathrm{HAB}}(\dot{\varepsilon}) D(\varepsilon)}{2 \dot{\varepsilon}},
\end{aligned}
$$

where $f_{\mathrm{HAB}}$ is the fraction of HABs and $v_{\mathrm{HAB}}$ is the grain boundary migration rate. The latter is given by the following relation:

$v_{\mathrm{HAB}}(\dot{\varepsilon})=v_{0}\left(\frac{\dot{\varepsilon}}{\dot{\varepsilon}_{0}}\right)^{m^{\prime}}$,

where $m^{\prime}$ is the strain rate sensitivity, and $v_{0}$ and $\dot{\varepsilon}_{0}$ are reference values.

The dislocation density $\left(\rho_{i}\right)$ can be used to determine the desired stress-strain curves:

$\sigma=G(T) b \sqrt{\rho_{i}(\varepsilon)}$,

where $G$ is the shear modulus and $b$ is the Burgers vector modulus.

Pure aluminum and aluminum alloys present a very large $r$ factor. A fraction of dislocations may be organized in low-angle boundaries with a misorientation angle $\theta_{0} \approx 1^{\circ}$, and the remaining fraction is absorbed by preexisting boundaries. $f_{\mathrm{LAB}}$ is obtained through an integration of $\varphi(\theta, \varepsilon)$ between angles of $1^{\circ}$ and $15^{\circ}$, and $f_{\mathrm{HAB}}$ is obtained from $1-f_{\mathrm{LAB}}$.

The subgrain size rate is composed of two contributions: a decreasing and an increasing term. Both are accounted for by considering subgrain formation and grain growth, respectively, as shown in the following relation:

$\frac{\mathrm{d} S(\varepsilon)}{\mathrm{d} \varepsilon}=\frac{b \alpha r(T, \dot{\varepsilon}) \rho_{i}(\varepsilon)}{n \theta_{0}}-\frac{f_{\mathrm{HAB}}(\varepsilon) S(\varepsilon)^{2} v_{\mathrm{HAB}}(\dot{\varepsilon})}{\dot{\varepsilon}}$,

where $\alpha$ is the dislocation partition coefficient and $S$ is the total area of the boundaries per unit volume, which is related to $D$ by means of the stereological relationship $D=2 / S$.

\section{The extended GM model}

Since alloys differ from pure metals because of the presence of solutes and precipitates, or second phases, which individually contribute to strengthening, Eq. (2) should be replaced by Eq. (6):

$$
\begin{aligned}
\frac{\mathrm{d} \rho_{i}(\varepsilon)}{\mathrm{d} \varepsilon}= & k_{D}+h(\dot{\varepsilon}, T)-r(\dot{\varepsilon}, T) \rho_{i}(\varepsilon) \\
& -\frac{\rho_{i}(\varepsilon) f_{\mathrm{HAB}}(\varepsilon) v_{\mathrm{HAB}}(\dot{\varepsilon}) D(\varepsilon)}{2 \dot{\varepsilon}},
\end{aligned}
$$

where $k_{D}$ is the precipitate-dislocation interaction coefficient that is used to take into account the second phase strengthening by relying on the Kocks-Mecking-Estrin (KME) theory for non-shareable precipitates [20]. $k_{D}$ is obtained from the following relation: 
$k_{D}=\alpha_{D} \frac{M}{b\left\langle r_{p}\right\rangle} \sqrt{\frac{f_{p}}{2 \pi}}$,

where $M$ is the Taylor factor, $\alpha_{D}$ is a constant close to 0.3 , and $f_{p}$ and $\left\langle r_{p}>\right.$ are the volume fraction and the average radius of spherical precipitates, respectively.

The contribution of solid solution strengthening is accounted for by making a slight modification of the original GM equation [15], which describes the $h$ parameter, whereas the equation describing the $r$ parameter remains unchanged. The two equations are as follows:

$h=h_{0}\left(\frac{\dot{\varepsilon}}{\dot{\varepsilon}_{0}}\right)^{m_{h}} \exp \left\{\frac{m_{h} Q_{h}}{R T}\right\}+h_{1}$,

$r=r_{0}\left(\frac{\dot{\varepsilon}}{\dot{\varepsilon_{0}}}\right)^{-m_{r}} \exp \left\{-\frac{m_{r} Q_{r}}{R T}\right\}$,

where $h_{0}, h_{1}, r_{0}, Q_{h}$, and $Q_{r}$ are unknown quantities of the alloy. The constants $h_{0}, h_{1}$, and $r_{0}$ are reference values, $R$ is the universal gas constant, $m_{h}$ and $m_{r}$ are the strain rate sensitivities, and $Q_{h}$ and $Q_{r}$ are the apparent activation energies (whose values are close to the activation energy for self-diffusion [14]). As Eqs. (4) and (6) describe the theoretical stress-strain curves of a given alloy, the $h$ and $r$ unknowns have to be estimated using the experimental stress-strain curves. Equation $8 \mathrm{a}, 8 \mathrm{~b}$ is used to extract the $h_{0}, h_{1}, r_{0}$, $m_{h}$ and $m_{r}$ material constants from a plane strain hot compression test [21], following the same procedure proposed by Gourdet [15].

\section{Model implementation}

The Al-2.5 wt\% Mg alloy (AA5052 [14]) has been used to test the developed model, which has been programmed in MATLAB ${ }^{\mathrm{TM}}$ language. The differential equation system (Eqs. 5 and 6) is solved with the Euler forward method. The model constants and initial conditions are summarized in Table 1, where $\rho_{i, i}$ is the initial dislocation density.

In order to overcome the aforementioned limitation [19] of the GM model concerning the determination of $f_{\mathrm{HAB}}$, the proposed CDRX model takes $f_{\mathrm{HAB}}$ as input data [10, 14]. Unlike the GM model, the misorientation angle $\theta$ of the given alloy is not taken into account, but the variables $D$ and $\rho_{i}$ are instead predicted by solving the coupled equation system (Eqs. 5 and 6). The procedure which is used to
Table 1 Constants and initial conditions used in the proposed model

\begin{tabular}{lll}
\hline Constant & Value & References \\
\hline$\rho_{i, i}$ & $0.1 \times 10^{12} \mathrm{~m}^{-2}$ & {$[10]$} \\
$f_{p}$ & 0.032 & {$[37]$} \\
$\left\langle r_{p}>\right.$ & $0.12 \mu \mathrm{m}$ & {$[37]$} \\
$\alpha$ & 0.1 & {$[15]$} \\
\hline
\end{tabular}

compute $f_{\mathrm{HAB}}$ is discussed in more detail in Appendix 1, all the other parameters being the same [15].

Since there is a lack of experimental data on the subgrain size of AA5052, data on A5024, on Al$1 \mathrm{wt} \% \mathrm{Mg}(\mathrm{Al}-1 \mathrm{Mg})$, and on $\mathrm{Al}-3 \mathrm{wt} \% \mathrm{Mg}(\mathrm{Al}-3 \mathrm{Mg})$ alloys have been used for sake of experimental validation. The initial grain size of the $\mathrm{Al}-1 \mathrm{Mg}$ alloy has been taken as $104 \mu \mathrm{m}$ [22]. A value of $80 \mu \mathrm{m}$ [14] has been chosen for the other alloys.

In the GM original work, $v_{0}$ was an experimental parameter that was set to $3 \mu \mathrm{m} \mathrm{s}^{-1}$ [15]. However, this value is unknown for aluminum alloys. A somewhat lower value than that measured for AA1200 can reasonably be expected for low alloying aluminum alloys, such as those considered in this work. In accordance with the GM model, we assume the same dependence on this parameter for both the dislocation density and grain size rate equations (Eqs. 5 and 6), but different $v_{0}$ values to account for the expected different dependence of $v_{0}$ on the strain rate in both equations. In prior numerical experiments, aimed at validating the proposed model against experimental subgrain size data and stressstrain curves, we found an identical $v_{0}$ value (3 $\mu \mathrm{m} \mathrm{s}^{-1}$ [15]) for the former and $0.3 \mu \mathrm{m} \mathrm{s}^{-1}$ for the latter. However, this latter value needs to be confirmed in the future through dedicated experiments in order to be considered physically acceptable.

\section{Model results and validation}

\section{Validation in terms of stress-strain curves}

The integration results from Eqs. (5) and (6) are shown in Figs. 1, 2, 3, 4, and 5. The experimental validation of the dislocation density versus time curves has been attained in terms of the stress-strain curves (Eq. 4) for AA5052.

As shown in Fig. 1, the stress-strain curves are influenced to a great extent by $k_{D}$. By taking into 


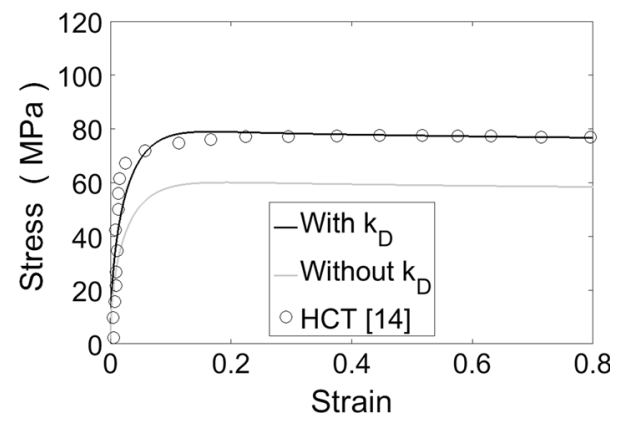

Figure 1 Comparison of stress-strain curves (with and without a $k_{D}$ contribution), computed with the proposed model, for AA5052 at a temperature of $333{ }^{\circ} \mathrm{C}$ and a strain rate of $0.01 \mathrm{~s}^{-1}$ against experiments [14].

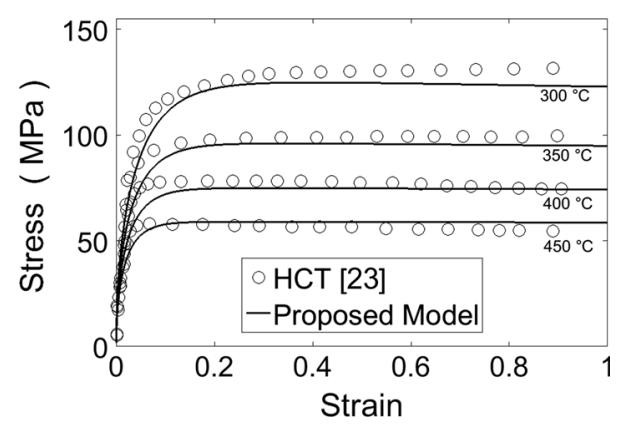

Figure 2 Comparison of stress-strain curves, computed with the proposed model, for AA5052 at a strain rate of $0.1 \mathrm{~s}^{-1}$ and over a range of temperatures $\left(300-450{ }^{\circ} \mathrm{C}\right)$ against experiments [23].

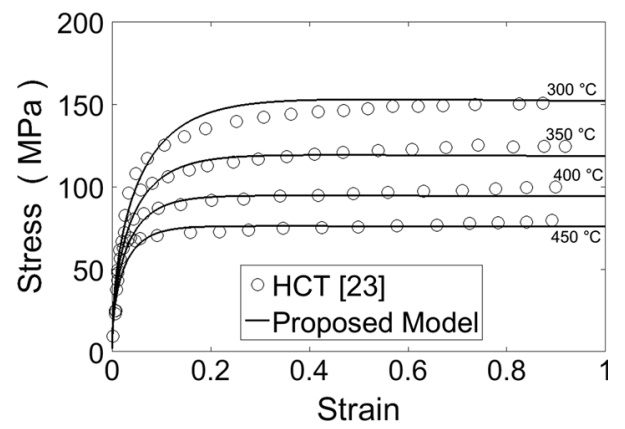

Figure 3 Comparison of stress-strain curves, computed with the proposed model, for AA5052 at a strain rate of $1 \mathrm{~s}^{-1}$ and over a range of temperatures $\left(300-450{ }^{\circ} \mathrm{C}\right)$ against experiments [23].

account $k_{D}$ and the values of $f_{p}$ and $\left\langle r_{p}>\right.$ from Table 1, the predicted steady-state flow of the stressstrain curve for AA5052 is approximately $20 \mathrm{MPa}$ higher than that without $k_{D}$. The curve predicted with the $k_{D}$ contribution is closer to experimental data. The predicted stress-strain curves are compared in Figs. 1, 2, 3, and 4 with HCT data at several

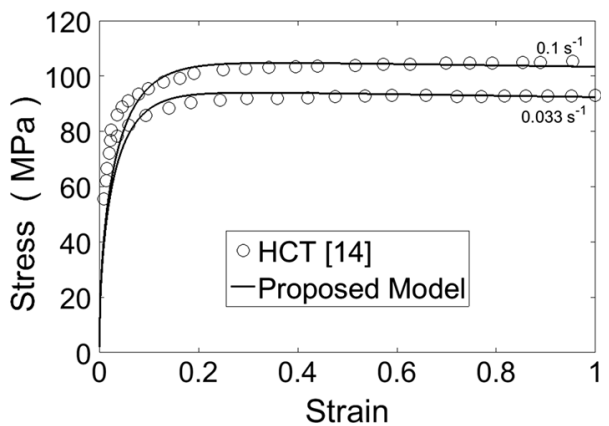

Figure 4 Comparison of stress-strain curves, computed with the proposed model, for AA5052 at a temperature of $333{ }^{\circ} \mathrm{C}$ and over a range of strain rates $\left(0.033-0.1 \mathrm{~s}^{-1}\right)$ against experiments [14].

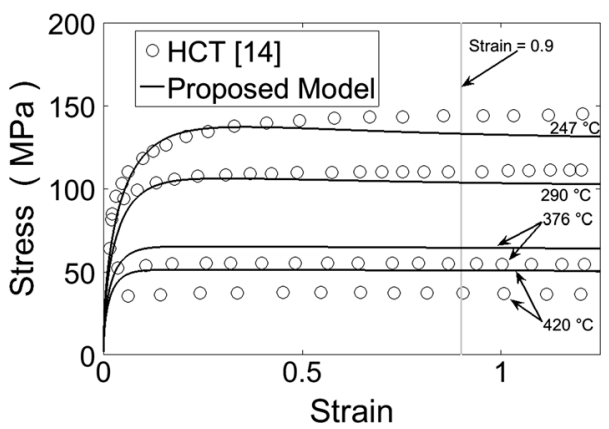

Figure 5 Comparison of stress-strain curves, computed with the proposed model, for AA5052 at a strain rate of $0.01 \mathrm{~s}^{-1}$ and over a range of temperatures $\left(247-420{ }^{\circ} \mathrm{C}\right)$. The vertical line at $\varepsilon=0.9$ highlights the steady-state flow values shown in Fig. 6 against experiments [14].

temperatures, strain rates $[14,23]$, and strains up to 1.2 , which is typical of a compression test. At initiation of plastic flow, the rapid increase in lattice dislocation density leads to strain hardening up to a strain of 0.2 (see Figs. 1, 2, 3, 4, and 5). Upon further strain, the number of lattice dislocations emitted by dislocation sources is equal to the number of dislocations annihilated due to dynamic recovery and absorbed by migrating HABs. As a result, apparent steady-state flow is observed as confirmed experimentally (Figs. 1, 2, 3, 4, and 5). The predicted curves are in good quantitative agreement with the experiments conducted at each temperature and strain rate higher than $0.01 \mathrm{~s}^{-1}$, up to $1 \mathrm{~s}^{-1}$, as illustrated in Figs. 2, 3, and 4. Figure 5 instead shows some deviations, due to the very low strain rate of $0.01 \mathrm{~s}^{-1}$, although a qualitative agreement can still be observed with the results of the experiments. The computed steady-state flow stress is compared with the measured one in Fig. 6. This figure not only 
summarizes the comparisons discussed in Figs. 1, 2, 3,4 , and 5 [14, 23], but also includes a comparison with a plane strain hot compression test (PSHCT) [21] pertaining to the stress at the steady state as a function of the Zener-Hollomon parameter $\left(Z=\dot{\varepsilon} \exp (Q / K T)\right.$, where $Q=156 \mathrm{~kJ} \mathrm{~mol}^{-1}$ is the activation energy [21]). $Z$ values were calculated for the temperature range $300-450{ }^{\circ} \mathrm{C}$ and strain rates ranging from 0.01 to $20 \mathrm{~s}^{-1}$. The model accuracy improves with increasing $Z$. The observed microstructure of AA5024 (Al-4.57 $w \mathrm{t} \% \mathrm{Mg}$ ) after ECAP at $300{ }^{\circ} \mathrm{C}$ and strains of up to 12 showed $\rho_{i}=2 \times 10^{14} \mathrm{~m}^{-2}$ [24]. However, the experimental strain rate value has not been given in this study as we assumed two cases, that is, $\dot{\varepsilon}=0.1 \mathrm{~s}^{-1}$ and $\dot{\varepsilon}=1 \mathrm{~s}^{-1}$, which are plausible values for severe plastic deformation processes [10, 25]. The predicted $\rho_{i}$ were $3.0 \times 10^{14} \mathrm{~m}^{-2}$ and $4.7 \times 10^{14} \mathrm{~m}^{-2}$, respectively, for AA5052, which are in good agreement with measurements [24].

\section{Validation in terms of subgrain size}

The predicted versus experimental (AA5052) [14] subgrain sizes at $0.01 \mathrm{~s}^{-1}$ and $333{ }^{\circ} \mathrm{C}$ are shown in Fig. 7. A marked grain refinement can be observed for smaller strains than 0.3 . The predictions and the experiments both exhibit the expected behavior on the subgrain size upon CDRX for larger strains than 0.3 , that is, the subgrain size decreases (slightly) for strains that are larger than 0.3 and less than approximately 0.9 , where the minimum in subgrain size is attained. An increase in subgrain size is predicted by the model for larger strains than 0.9 , in

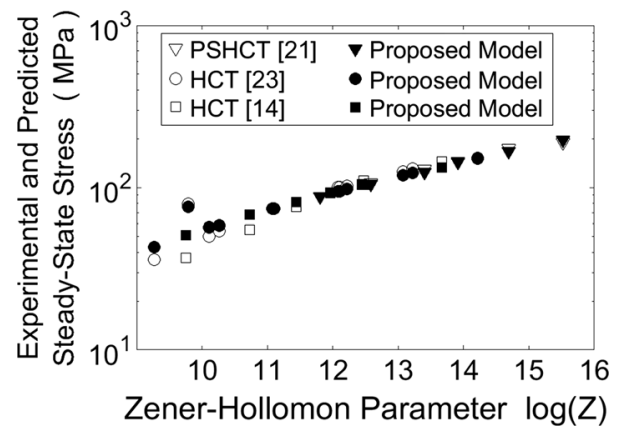

Figure 6 Comparison of the steady-state stress as a function of the Zener-Hollomon parameter, computed with the proposed model, against experimental PSHCT [21] and HCT [14, 23] data for AA5052 over a range of temperatures $\left(300-450{ }^{\circ} \mathrm{C}\right)$ and strain rates $\left(0.01-20 \mathrm{~s}^{-1}\right), \varepsilon=0.9$ and $Q=156 \mathrm{~kJ} \mathrm{~mol}^{-1}$.

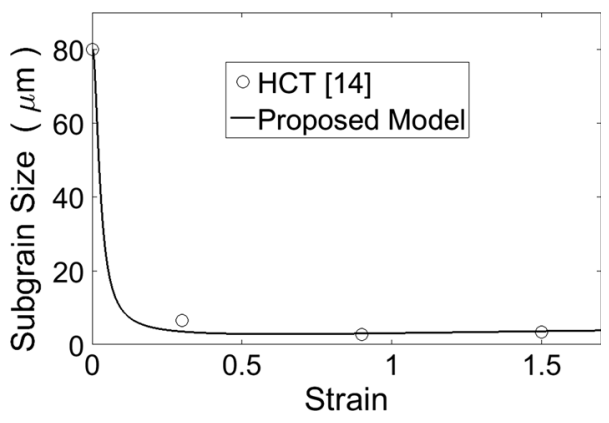

Figure 7 Comparison of the subgrain size, computed with the proposed model, for AA5052 at a temperature of $333{ }^{\circ} \mathrm{C}$ and a strain rate of $0.01 \mathrm{~s}^{-1}$ against experiments [14].

agreement with the experiments, although this grain growth is not significant in the case of Fig. 7. In this respect, the proposed model provides a quantitative agreement with the experiments on grain refinement and subsequent grain growth in AA5052 in the strain range up to 1.5. An analogous comparison is shown in Fig. 8, with respect to the Zener-Hollomon parameter for a plane strain compression test [22] on $\mathrm{Al}-1 \mathrm{Mg}$ alloy at one single strain $\varepsilon=1,300-450{ }^{\circ} \mathrm{C}$, and $0.25-25 \mathrm{~s}^{-1}$. Despite different alloys being used in this test, the qualitative agreement is good. The deviation in the measured and predicted subgrain size decreases as $Z$ increases. The subgrain size decreases with increasing $Z$. Figure 9 compares the computed subgrain sizes with measured $[14,22,24,26,27]$ ones. This figure contains the results of the comparisons discussed in Figs. 7 and 8 $[14,22]$ as well as those with ECAP experiments as a function of the Zener-Hollomon parameter for single strains, namely 5.6 [24] and 12 [26, 27], with Z comprising $300-450{ }^{\circ} \mathrm{C}$ and $0.01-25 \mathrm{~s}^{-1}$ range values.

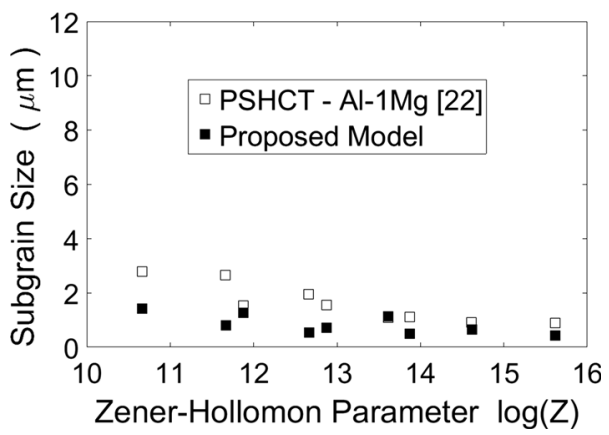

Figure 8 Comparison of the subgrain size, computed at $\varepsilon=1$ as a function of Zener-Hollomon parameter for AA5052, against experimental data for the Al-1Mg alloy [22] at different temperatures $\left(300-450{ }^{\circ} \mathrm{C}\right)$ and strain rates $\left(0.25-25 \mathrm{~s}^{-1}\right)$; $Q=156 \mathrm{~kJ} \mathrm{~mol}^{-1}$. 


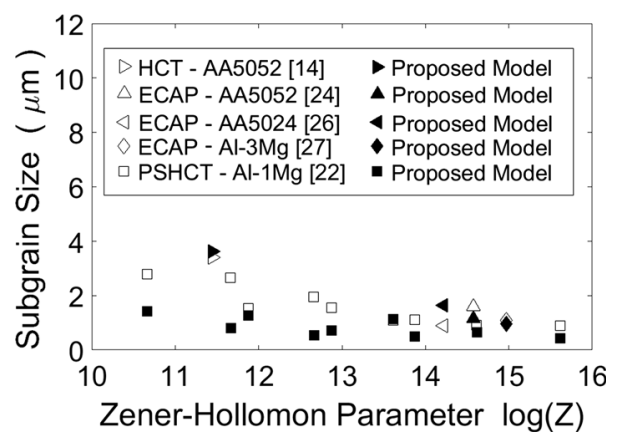

Figure 9 Comparison of the subgrain size, computed for one single strain (from $\varepsilon=1$ to $\varepsilon=12$ ) as a function of the ZenerHollomon parameter for AA5052, against experimental data $[14,22,24,26,27]$ pertaining to four Al-Mg alloys over a range of temperatures $\left(300-450{ }^{\circ} \mathrm{C}\right)$ and strain rates $\left(0.01-25 \mathrm{~s}^{-1}\right)$; $Q=156 \mathrm{~kJ} \mathrm{~mol}^{-1}$.

\section{Discussion}

In consideration of the criticism [19] advanced on the reliability of the GM model for the prediction of $f_{\mathrm{HAB}}$, we have attempted to overcome this problem using an experimentally based $[10,14] f_{\mathrm{HAB}}-\varepsilon$ law (Eq. 10) for AA5052. Thus, $f_{\mathrm{HAB}}-\varepsilon$ was not calculated by the model but was assumed as known from experimental data for the selected alloy. Relying on [25], we assumed that the $f_{\mathrm{HAB}}-\varepsilon$ data are independent of the strain rate and temperature. This $f_{\mathrm{HAB}}-\varepsilon$ law, which was taken from the best fitting of experimental data, was used as input for the model. This strategy is advantageous when it is not possible to accurately predict the distribution of the misorientation angle as a function of the elements and strain of an alloy. This choice was supported by a prior investigation on the original GM model which suggested that the distribution of the misorientation angle does not depend to a great extent on the strain rate and temperature. This is another way of saying that the $f_{\mathrm{HAB}}-\varepsilon$ law (or the integral of the distribution of the misorientation angle [15]) is decoupled from the evolution equations (Eqs. 5 and 6), and it can therefore be defined for any given alloy once and for all at the beginning of the CDRX simulation. In so doing, we have found that the best fit of the $f_{\mathrm{HAB}}-\varepsilon$ law for AA5052 was in qualitative agreement with other observed laws pertaining to other aluminum alloys in the observed 20-400 ${ }^{\circ} \mathrm{C}$ range and for larger strains than 1 [25]. Owing to the close qualitative and quantitative similarity of these $f_{\mathrm{HAB}}-\varepsilon$ laws for several engineering alloys [25] (excluding AA1200 of the 1xxx series for which a more specific $f_{\mathrm{HAB}}-\varepsilon$ law should be given), we defined a typical $f_{\mathrm{HAB}}-\varepsilon$ relationship for AA5052 in order to simulate CDRX in this alloy.

There is a lack of experimental data on $f_{\mathrm{HAB}}$, on the subgrain size, and on the stress-strain curve for varying temperature and strain rates, especially for AA5052. For model validation purposes, the predicted stress-strain curves and subgrain size were compared with experimental data taken from hot compression tests $[14,23]$ and plane strain hot compression tests [21, 22], and ECAP data [24, 26, 27] were used for larger strains than 1.5 [24, 26, 27].

It should be noted that the absence of a pronounced stress peak before the steady-state flow in stress-strain curves implies that DDRX cannot occur [28]. The predicted stress-strain curves did not exhibit a pronounced peak before the steady-state flow for AA5052, a result which is in quantitative agreement with experimental data for the same alloy with HCT [14, 23] and PSHCT [21] and in qualitative agreement with that of the Al-1Mg alloy with PSHCT [29-31] as well as with predictions for AA1200 [15].The temperature and strain rate dependence on flow stress were found to be in agreement with classical observations [28], in that flow stress increases with increasing strain rate and decreasing temperature. The predicted curves, when taking into account precipitate strengthening, were closer to the experiments. The $k_{D}$ term (in Eq. 6) is of crucial importance for a reliable description of the strain hardening behavior of AA5052. The importance of $k_{D}$ factor in similar model was also emphasized by other authors [20]. The dispersion of experimental data may influence the value of $k_{D}$ to a certain extent (through $f_{p}$ and $\left\langle r_{p}\right\rangle$ ) and thereby affect the stressstrain curves and, perhaps, also the subgrain size. Numerical experiments conducted previously using the extended model showed that an intentional change of approximately $\pm 20 \%$ to the $f_{p}$ and $\left\langle r_{p}\right\rangle$ parameters affected the strengthening caused by $k_{D}$ by approximately $20 \mathrm{MPa}$. This corresponds to $\pm 4 \mathrm{MPa}$ of the steady-state flow value, which has a different impact, depending on the strain rate and temperature conditions. In other words, a high temperature and low strain rate will be more sensitive to changes in $k_{D}$.

As can be observed in Fig. 5, lower strain rates, such as one of $0.01 \mathrm{~s}^{-1}$, lead to larger deviations than higher strain rates, since they are far from the calibration range of $0.1-20 \mathrm{~s}^{-1}$ (Fig. 6). In turn, this 
deviation affects the estimation accuracy of $h$ and $r$ at low strain rates. Figure 6 shows that the agreement between the predicted and experimental data $[14,21,23]$ is quite good for a strain of 0.9 . This points out the advantage of applying the model to hot rolling, since $\varepsilon=0.9$ is taken as the upper limit for this process [3, 32].

As can be seen in Fig. 7, the prediction of the subgrain size as a function of strain confirms that CDRX provides significant grain refinement during ECAP [10, 22, 33, 34] and HCT [14] experiments. However, subgrain formation has also been investigated during the hot rolling of Al-1Mn-1Mg alloy [35]. The grain size was markedly refined (initial grain size of $100 \mu \mathrm{m})$ down to a $1.8 \mu \mathrm{m}$ subgrain size after reversible rolling and to $0.7-1.5 \mu \mathrm{m}$ after tandem rolling [35]. This result was in qualitative agreement with the grain refinement predicted here for AA5052 (Fig. 9), thereby further supporting the application of the developed extended model to industrial hot rolling.

Another attempt had been made to promote an ultra-fine grain structure using the combination of hot rolling and PSHCT on an $\mathrm{Al}-3 \mathrm{Mg}-0.2 \mathrm{Cr}-0.2 \mathrm{Fe}$ alloy exhibiting an initial grain size of $1-3 \mathrm{~mm}$ (before hot rolling) and attaining a final subgrain size of up to $1.5 \mu \mathrm{m}$ (after PSHCT) [33]. On the basis of the results of experiments on AA5052 [14] and Al-Li$\mathrm{Mg}-\mathrm{Sc}[10]$, this subgrain refinement had a minimum value for critical strain values of approximately 0.9 and 4, respectively. The proposed model has in fact been able to capture this critical value for AA5052, although by a broad minimum, located between 0.5 and 0.9 strain. This minimum subgrain size was not appreciated with the GM model. It emerged in this model because subgrain growth resulted from two factors, namely $v_{\mathrm{HAB}}$ and $f_{\mathrm{HAB}}$. The former was assumed as a constant (as in the GM model), whereas the latter (Fig. 10) increased for an increasing strain above 0.5 (unlike the constant value used in the GM model). In the proposed CDRX model, the input $f_{\mathrm{HAB}}$ function is determined from experimental data. As this function influences the accuracy of the predicted subgrain size to a great extent, other numerical simulations were carried out with the aim of evaluating the effect of its changes (e.g., $\pm 20 \%$ ) on the predicted final subgrain size. The results show that the subgrain size is not affected by $f_{\mathrm{HAB}}$ for strains below 0.5 . On the other hand, for larger strains, such as $\varepsilon=1.5$ (reference value), a $\pm 20 \%$ change in $f_{\mathrm{HAB}}$ translates into a $\pm 10 \%$ change in the computed subgrain size.

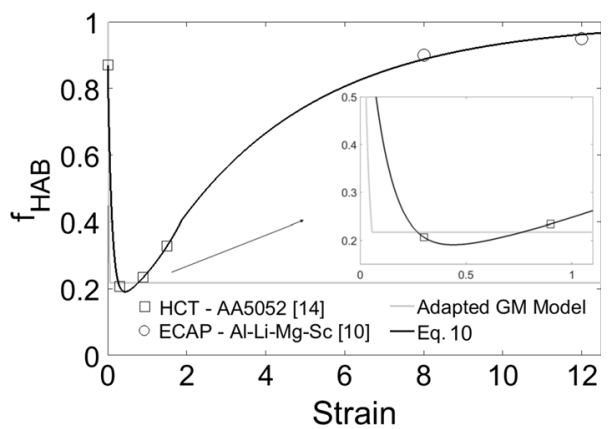

Figure 10 Best fitted $f_{\mathrm{HAB}}-\varepsilon$ law (Eq. 10) against HCT experiments for $\mathrm{A} 5052$ at $333{ }^{\circ} \mathrm{C}$ and $0.01 \mathrm{~s}^{-1}$ [14], ECAP experiments for $\mathrm{Al}-\mathrm{Li}-\mathrm{Mg}-\mathrm{Sc}$ alloy at $300{ }^{\circ} \mathrm{C}$ and $0.1 \mathrm{~s}^{-1}$ [10] and against the extended GM model predictions using the input data given in Table 1 for AA5052 at $333{ }^{\circ} \mathrm{C}$ and $0.01 \mathrm{~s}^{-1}$.

This change could initially be considered significant; however, when this change is associated with a relatively very small value of the predicted subgrain size, such as $3.6 \mu \mathrm{m}$, this change effect may be considered practically irrelevant and even hard to detect with conventional measuring devices. The predictions made with the original GM model [15] show that the initial grain size does not influence the subgrain size achieved for AA1200 for a large strain $(\varepsilon>3)$. It should be noted that a steady state occurs for sufficiently large strains (depending on the alloy and the deformation conditions), in which the microstructure (e.g., the subgrain size) does not depend on the initial grain size. This is a basic property of the steady state.

According to GM [15], using this extended model, a change of $\pm 20 \%$ of the initial grain size does not affect the predicted subgrain size in AA5052 for a large strain. Moreover, since the grain refinement is more effective in the given alloy, the change in the initial grain size is limited to only a very few increments of strains $(\varepsilon<0.1)$. The predicted subgrain size, as a function of the Zener-Hollomon factor (Fig. 8), was slightly underestimated, compared to the PSHCT data of the Al-1Mg alloy. In this case, the smaller magnesium content in the $\mathrm{Al}-1 \mathrm{Mg}$ alloy may be responsible for a smaller volume fraction of precipitates, and a consequent lower efficiency in grain boundary pinning [36]. Conversely, this may result in a greater subgrain growth in $\mathrm{Al}-1 \mathrm{Mg}$ alloy than in AA5052 and, consequently, to a smaller subgrain size. As the temperature decreases (resp. increases in $Z$ ), the grain growth term becomes increasingly weaker, and the model deviation increasingly lower. 
A good quantitative agreement (Fig. 9) was instead achieved for very large strains (e.g., $\varepsilon=5.6$ ), as the predicted subgrain size was very close to that measured by ECAP for the same AA5052 [26]. A similar agreement was attained when the model results were compared with ECAP data for both AA5024 and Al$3 \mathrm{Mg}$ alloy at $\varepsilon=12$. The predicted dislocation density compared quite well with the ECAP measurements for one single strain (e.g., $\varepsilon=12$ ) for AA5024.

Thus, it is possible to state that the proposed extended CDRX model is consistent with the CDRX phenomena exhibited by the AA5052 alloy during hot laboratory tests. The availability of appropriate hot rolling data will further support the use of this model as a guiding tool to control industrial-scale CDRX phenomena of aluminum alloys.

\section{Conclusions}

A modification of the original Gourdet-Montheillet CDRX model has been developed and validated for a wrought A5052 alloy using experimental data from simulated hot laboratory tests. The $f_{\mathrm{HAB}}-\varepsilon$ input law was first determined as a best fitting function of experimental data and assumed to be decoupled from the evolution of dislocation kinetics, thereby as being temperature and strain rate independent. The resulting $f_{\mathrm{HAB}}-\varepsilon$ law was found to be in qualitative agreement with several hot and cold simulated laboratory experiments for various strain rates.

Solid solution strengthening was taken into account by means of the ad hoc definition of the $h$ and $r$ kinetic parameters for AA5052. Precipitation strengthening was taken into account by means of the KME theory. The model was experimentally validated against HCT, PSHCT, and ECAP laboratory experiments. It was found that the predicted stressstrain curves, dislocation density, and subgrain size were in good agreement with the outcomes of laboratory tests. A sensitivity analysis conducted on the most relevant model parameters $\left(f_{\mathrm{HAB}},\left\langle r_{p}>, f_{p}\right.\right.$ and the initial grain size) revealed that the steady-state flow is more sensitive to $\left\langle r_{p}\right\rangle$ and $f_{p}$, especially at high temperatures and for low strain rates. The subgrain size is more sensitive to the initial grain size for strains below 0.1 , whereas it is not affected for strains equal to or larger than 0.1 at $333{ }^{\circ} \mathrm{C}$ and $0.01 \mathrm{~s}^{-1}$. The model can be considered as a first step toward the actual control of CDRX on wrought aluminum alloys at an industrial scale.

\section{Compliance with ethical standards}

Conflict of interest The authors declare that they have no conflict of interest.

\section{Appendix 1}

The $f_{\mathrm{HAB}}$ computed by the GM model has been criticized as being unrealistic [19]. GM predicted that $f_{\mathrm{HAB}}$ decreased with increasing plastic strain, until it reached a plateau at approximately 0.2 . Conversely, ECAP experiments have shown that the $\mathrm{Al}-\mathrm{Li}-\mathrm{Mg}-$ Sc alloy could achieve $f_{\mathrm{HAB}}>0.9$ for larger strains than 8 [10], as shown in Fig. 10. In order to resolve this inconsistency, we fitted $f_{\mathrm{HAB}}$ data from a hot compression test for AA5052 [14] using Eq. (9):

$f_{\mathrm{HAB}}=K_{1} \exp \left\{K_{2} \varepsilon\right\}+K_{3} \exp \left\{K_{4} \varepsilon\right\}$

As shown in Fig. 11, the $f_{\mathrm{HAB}}$ value in Eq. (9) can reach greater values than 1 for larger strains than 3.5, which is physically unacceptable. A more realistic relationship between $f_{\mathrm{HAB}}$ and $\varepsilon$ for the A5052 alloy under study can be achieved by fitting ECAP experiment $\left(\varepsilon>8,300{ }^{\circ} \mathrm{C}\right.$ and $\left.0.1 \mathrm{~s}^{-1}\right)$ and compression data $\left(\varepsilon<2,333{ }^{\circ} \mathrm{C}\right.$ and $\left.0.01 \mathrm{~s}^{-1}\right)$ for the Al-Li-Mg-Sc [10] and A5052 [14] alloys, respectively, using the following piecewise-defined function:

$f_{\mathrm{HAB}}= \begin{cases}K_{1} \exp \left\{K_{2} \varepsilon\right\}+K_{3} \exp \left\{K_{4} \varepsilon\right\}, & \varepsilon<1.9 \\ 1-K_{5} \exp \left\{-K_{6} \varepsilon\right\}, & \varepsilon \geq 1.9\end{cases}$

$(10 \mathrm{a}, \mathrm{b})$

As shown in [25], even very different aluminum alloys can exhibit qualitatively similar $f_{\mathrm{HAB}}-\varepsilon$ laws.

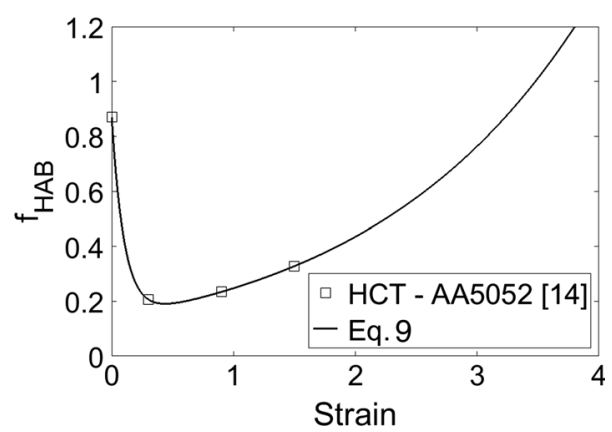

Figure 11 Best fitted $f_{\mathrm{HAB}}-\varepsilon$ law (Eq. 9) compared with $\mathrm{HCT}$ experiments for A5052 at $333{ }^{\circ} \mathrm{C}$ and $0.01 \mathrm{~s}^{-1}$ [14]. 
Table 2 Coefficients used in Eqs. (9) and (10)

\begin{tabular}{lrll}
\hline Coefficient & \multicolumn{1}{l}{ Value } & Coefficient & Value \\
\hline$K_{1}$ & 0.7292 & $K_{4}$ & 0.5637 \\
$K_{2}$ & -9.6570 & $K_{5}$ & 0.9906 \\
$K_{3}$ & 0.1408 & $K_{6}$ & 0.2717 \\
\hline
\end{tabular}

This implies that considering the lack of more specific data on AA5052, the $f_{\mathrm{HAB}}-\varepsilon$ law (Eq. 10) of the latter could be approximated with that of $\mathrm{Al}-\mathrm{Li}-\mathrm{Mg}-$ Sc with the constants listed in Table 2. These model parameters are quite sensitive.

Figure 10 shows the results of the best fitting. Initially, the fraction of HABs was close to 0.9 , and it then dropped to 0.2 at $\varepsilon=0.5$. For $\varepsilon>0.5, f_{\mathrm{HAB}}$ increased with increasing strain and asymptotically approached $f_{\mathrm{HAB}}=1$. The use of empirical Eq. (10) was found to be effective in describing the overall $f_{\mathrm{HAB}}-\varepsilon$ law for both low strains (Eq. 10a for $\varepsilon<1.9$ ) and high strains (Eq. 10b, for $\varepsilon>1.9$ ), which are typical of hot rolling and severe plastic deformation, respectively. However, there was a lack of experimental data on the influence of the temperature and strain rate on $f_{\mathrm{HAB}}-\varepsilon$ law for the AA5052 even though it was possible to show that the influence of the temperatures and strain rates on $f_{\mathrm{HAB}}$, predicted by means of the GM model [15], was negligible for AA1200 over the $277-460{ }^{\circ} \mathrm{C}$ and $0.01-1 \mathrm{~s}^{-1}$ ranges. Moreover, certain experiments [25] have shown that $f_{\mathrm{HAB}}-\varepsilon$ data of a large set of $\mathrm{Al}-\mathrm{Mg}$ alloys fit well with one single curve for different temperatures (over the $20-400{ }^{\circ} \mathrm{C}$ range) and for larger strains than $\varepsilon=1$. Thus, it was reasonable to assume that Eq. (10) had to be independent of the temperature and strain rates.

Preliminary attempts were made with the aim of calculating $f_{\mathrm{HAB}}$ by applying GM model [15] to AA5052 by simply adjusting the model parameters. The result is shown in Fig. 10. As can be seen, the predicted $f_{\mathrm{HAB}}$ started from 1 and dropped to a plateau of 0.22 , even after very small strains, unlike what was found in experiments [10, 14, 25].

\section{References}

[1] Hirsch J, Grenz R (1998) Microstructure control on an aluminium hot reversing finishing mill. In: Bieler $\mathrm{T}$ et al (eds)
Hot deformation of aluminum alloys II. TMS Symposium, Illinois, pp 305-316

[2] Hirsch J, Karhausen KF, Engler O (2004) Property control in production of aluminum sheet by use of simulation. In: Roters F, Barlat F, Chen LQ, Raabe D (eds) Continuum scale simulation of engineering materials: fundamentals-microstructures - process applications. Wiley-VCH Verlag GmbH \& Co. KGaA, Weinheim

[3] Vatne HE, Marthinsen K, Ørsund R, Nes E (1996) Modeling recrystallization kinetics, grain sizes, and textures during multipass hot rolling. Metall Mater Trans A 27(12):4133-4144

[4] Humphreys FJ, Hatherly M (2004) Recrystallization and related annealing phenomena. Elsevier, Amsterdam ISBN:978-0-08-044164-1

[5] Wells MA, Lloyd DJ, Samarasekera IV, Brimacombe K, Hawbolt EB (1998) Modeling the microstructural changes during hot tandem rolling of AA5XXX aluminum alloys: Part I. Microstructural evolution. Metall Mater Trans B 29(3):611-620

[6] Huang K, Logé RE (2016) A review of dynamic recrystallization phenomena in metallic materials. Mater Des 111:548-574

[7] Yamagata H (1995) Dynamic recrystallization and dynamic recovery in pure aluminum at $583 \mathrm{~K}$. Acta Metall et Mater 43(2):723-729

[8] Sakai T, Belyakov A, Kaibyshev R, Miura H, Jonas JJ (2014) Dynamic and post-dynamic recrystallization under hot, cold and severe plastic deformation conditions. Prog Mater Sci 60:130-207

[9] McQueen HJ, Cellier OC (1996) Application of hot workability studies to extrusion processing: Part II. Microstructural development and extrusion of $\mathrm{Al}, \mathrm{Al}-\mathrm{Mg}$, and $\mathrm{Al}-\mathrm{Mg}-\mathrm{Mn}$ alloys. Can Metall Q 35(4):305-319

[10] Kaibyshev R, Shipilova K, Musin F, Motohashi Y (2005) Continuous dynamic recrystallization in an $\mathrm{Al}-\mathrm{Li}-\mathrm{Mg}-\mathrm{Sc}$ alloy during equal-channel angular extrusion. Mater Sci Eng A 396:341-351

[11] McQueen HJ, Knustad O, Ryum N, Solberg JK (1985) Microstructural evolution in Al deformed to strains of 60 at $400^{\circ}$ C. Scripta Metall 19(1):73-78

[12] De Pari L, Jr Misiolek WZ (2008) Theoretical predictions and experimental verification of surface grain structure evolution for AA6061 during hot rolling. Acta Mater 56(20):6174-6185

[13] Lyttle MT, Wert JA (1994) Modelling of continuous recrystallization in aluminum alloys. $\mathrm{J}$ Mater Sci 29:3342-3350. https://doi.org/10.1007/BF00356683

[14] Gourdet S (1997) Etude des mecanismes de recristallisation au cours de la deformation a chaud de l'aluminium. Ph.D. 
Thesis. Saint-Etienne: Material chemistry. Ecole Nationale Superieure des Mines de Saint-Etienne

[15] Gourdet S, Montheillet F (2003) A model of continuous dynamic recristallization. Acta Mater 51(03):1359-6454

[16] Le KC, Kochmann DM (2009) A simple model for dynamic recrystallization during severe plastic deformation. Arch Appl Mech 79:579-586

[17] Fischer FD, Schmid E (2007) Moving interfaces in crystalline solids. Springer, London ISBN:3-211-23899-9

[18] Taylor GI, Quinney H (1934) The latent energy remaining in a metal after cold working. Proc R Soc A 143:307-326

[19] McQueen HJ, Kassner ME (2004) Comments on "a model of continuous dynamic recrystallization” proposed for aluminum. Scripta Mater 51:461-465

[20] Bahrami A (2010) Ph.D. thesis - modeling of precipitation sequence and ageing kinetics in $\mathrm{Al}-\mathrm{Mg}-\mathrm{Si}$ alloys

[21] Kowalski B, Lacey AJ, Sellars CM (2003) Correction of plane strain compression data for the effects of inhomogeneous deformation. Mater Sci Technol 19(11):1564-1570

[22] Furu T, Ørsund R, Nes E (1996) Substructure evolution during different hot deformation processes of commercial non-heat treatable aluminum alloys. Mater Sci Eng A 214:I22-I32

[23] Wang Y, Peng J, Zhong L, Pan F (2016) Modeling and application of constitutive model considering the compensation of strain during hot deformation. J Alloy Compd 681:455-470

[24] Mogucheva A, Babich E, Ovsyannikov B, Kaibyshev R (2013) Microstructural evolution in a 5024 aluminum alloy processed by ECAP with and without back pressure. Mater Sci Eng: A 560:178-192

[25] Sitdikov O, Sakai T, Avtokratova E, Kaibyshev R, Kimura Y, Tsuzaki K (2007) Grain refinement in a commercial Al-MgSc alloy under hot ECAP conditions. Mater Sci Eng A 444(1):18-30

[26] Chen YC, Huang YY, Chang CP, Kao PW (2003) The effect of extrusion temperature on the development of deformation microstructures in 5052 aluminium alloy processed by equal channel angular extrusion. Acta Mater 51(7):2005-2015
[27] Yamashita A, Yamaguchi D, Horita Z, Langdon TG (2000) Influence of pressing temperature on microstructural development in equal-channel angular pressing. Mater Sci Eng A 287(1):100-106

[28] Guo-Zheng Q (2013) Characterization for dynamic recrystallization kinetics based on stress-strain curves. In: Wilson $\mathrm{P}$ (ed) Recent developments in the study of recrystallization

[29] Beynon JH, Sellars CM (1992) Modelling microstructure and its effects during multipass hot rolling. ISIJ Int 32(3):359-367

[30] Hirsch J (2009) Hot formability and texture formation in Al alloys. Mater Sci Forum 604:259-266

[31] Tang JG, Huang XX, Zhang XM (2012) Hot-compression behavior of Al alloy 5182. J Cent South Univ 19:2073-2080

[32] Wang CS, Wang HX, Li JB, Zhang J (2011) Experiment on hot rolling deformation resistance of aluminum alloy and mathematical modeling. Adv Mater Res 314:409-414

[33] Gholinia A, Humphreys FJ, Prangnell PB (2002) Production of ultra-fine grain microstructures in $\mathrm{Al}-\mathrm{Mg}$ alloys by coventional rolling. Acta Mater 50(18):4461-4476

[34] Duly D, Baxter GJ, Shercliff HR, Whiteman JA, Sellars CM, Ashby MF (1996) Microstructure and local crystallographic evolution in an $\mathrm{Al}-1 \mathrm{wt} \% \mathrm{Mg}$ alloy deformed at intermediate temperature and high strain-rate. Acta Mater 44(7):2947-2962

[35] Daaland O, Nes E (1996) Origin of cube texture during hot rolling of commercial Al-Mn-Mg alloys. Acta Mater 44(4):1389-1411

[36] Doherty RD, Hughes DA, Humphreys FJ, Jonas JJ, Jensen DJ, Kassner ME, King WE, McNelley TR, McQueen HJ, Rollett AD (1997) Current issues in recrystallization: a review. Mater Sci Eng A 238:219-274

[37] Carmona R, Zhu Q, Sellars CM, Beynon JH (2005) Controlling mechanisms of deformation of AA5052 aluminium alloy at small strains under hot working conditions. Mater Sci Eng A 393:157-163 